Acta vet. scand. 1970, 11, 329-330.

Brief Communication

\title{
URINARY OESTROGENS IN OVARIECTOMIZED COWS AFTER ADMINISTRATION OF ACTH
}

Two ovariectomized cows were injected intramuscularly once daily with 300 i.u. of $\mathrm{ACTH}^{\star}$ ) on three consecutive days. The urine was collected with the aid of rubber mats. The method for oestrogen analysis comprised acid hydrolysis of the urine, saponification of the phenolic fraction, methylation and column chromatography followed by fluorimetry (Lunaas 1964 and unpublished).

A convincing response to ACTH was obtained only in Cow A (Table 1) in which the urinary excretion of oestrogens increased by an apparent factor of 5-10 and approached levels found in intact cows during oestrus (unpublished results). The seemingly much weaker response in Cow $B$ could in part have been due to a differing peripheral metabolism of oestrogens; the urinary excretion of oestrogens in this animal on the day after intravenous injection of $500 \mu \mathrm{g}$ oestradiol-17 $\beta$ amounted only to about $1 / 3$ of that in the other (Table 1 ).

$\mathrm{Table} 1$. Urinary oestrone $\left(\mathrm{Oe}_{1}\right)$ and oestradiol-17 $\alpha\left(\mathrm{Oe}_{2}\right)$ in ovariectomized cows given 300 i.u. ACTH i.m. per day for three consecutive days.

\begin{tabular}{|c|c|c|c|c|c|}
\hline & \multirow{3}{*}{ Day } & \multicolumn{4}{|c|}{$\mu \mathrm{g}$ per $24 \mathrm{hrs}$} \\
\hline & & \multicolumn{2}{|c|}{ Cow A } & \multicolumn{2}{|c|}{ Cow B } \\
\hline & & $\mathrm{Oe}_{1}$ & $\mathrm{Oe}_{2}$ & $O \mathbf{e}_{1}$ & $\mathrm{Oe}_{2}$ \\
\hline Before & 2 & 3.0 & 2.3 & 3.1 & 3.1 \\
\hline ACTH & 1 & 2.1 & 1.4 & 1.2 & 1.2 \\
\hline After first & 1 & 3.8 & 3.8 & 1.2 & 2.4 \\
\hline ACTH & 2 & 4.3 & 5.0 & 1.8 & 3.6 \\
\hline \multirow[t]{5}{*}{ injection } & 3 & 9.8 & 20.5 & 1.9 & 7.6 \\
\hline & 4 & 4.5 & 12.2 & 4.8 & 3.2 \\
\hline & 5 & 5.0 & 6.4 & 1.8 & 1.2 \\
\hline & 6 & 4.5 & 4.5 & 1.0 & 3.3 \\
\hline & 7 & 1.3 & 1.7 & 4.4 & 4.4 \\
\hline After oestra- & 1 & 25.9 & 123.2 & 13.5 & 44.1 \\
\hline diol-17 $\beta$, & 2 & 2.8 & 19.8 & 5.8 & 15.9 \\
\hline $500 \mu \mathrm{g}$ i.v. & 3 & 1.4 & 4.8 & 0.9 & 2.7 \\
\hline
\end{tabular}

*) ACTH prolongatum, Batch 2004, Fredriksberg Chemiske Fabriker A/S. 
Increased excretion of oestrogens in cows treated with ACTH would be consistant with the finding that the bovine adrenal cortex contains oestrone (Beall 1940). Release of oestrone from the adrenals would give rise to oestradiol- $17 \alpha$ as the major urinary metabolite. Peripheral aromatisation of various androgens or other steroids of adrenal origin might be considered as an alternative mode of adrenal contribution to the all over endogenous production of oestrogens. Judging from the few data presented the response, if any, to exogenous ACTH with respect to oestrogen excretion in the cow seems to be a rather delayed one or slow to develop. Quite similar patterns of oestrogen excretion have been observed after ACTH administration in ovariectomized women (Brown et al. 1959).

\section{Torleiv Lunaas}

Department of Reproductive Physiology and Pathology, Veterinary College of Norway, Oslo.

\section{REFERENCES}

Beall, D.: The isolation of oestrone from ox adrenals. J. Endocr. 1940, $2,81-87$.

Brown, J. B., C. W. A. Falconer \& J. A. Strong: Urinary oestrogens of adrenal origin in women with breast cancer. J. Endocr. 1959, $19,52-63$.

Lunaas, T.: Spectrophotometric methods for the analysis of mixtures of oestradiol-17 $\alpha$ and oestradiol-17 $\beta$. Acta chem. scand. 1964, $18,321-328$.

(Received April 22, 1970). 